\title{
To the determination of heat exchange conditions near the inner surface of walls with reflective thermal insulation from aluminium foil
}

\author{
Nina Umnyakova ${ }^{1, *}$, and Mikhail Gandzhuntsev ${ }^{2}$ \\ ${ }^{1}$ NIISF RAABS, 21, Lokomotovnij pr., Moscow, 127238, Russia \\ ${ }^{2}$ Moscow State University of Civil Engineering, Yaroslavskoe sh., 26, Moscow, 129337, Russia
}

\begin{abstract}
Materials with a low coefficient of surface radiation intensively reflect the radiant component of the heat flux and reduce heat losses through the building envelope. When designing building structures with reflective thermal insulation it is necessary to evaluate the efficiency of its application. However, at present there are no methods for calculating the value of thermal losses through external walls in the presence of reflective thermal insulation on internal surface of the wall, as well as there are no data on the values of heat transfer coefficients at the inner surface of building envelope with reflective thermal insulation. In this regard, in the climatic chambers of NIISF RAABS, complex thermal engineering studies were carried out. For this a cellular concrete wall $2,8 \times 1,2 \mathrm{~m}$ was put up into the chamber with reflective thermal insulation on the inner surface and without it. The obtained results of experimental studies, presented in the work, allowed obtaining numerical values of heat transfer coefficients at the inner surface of walls with reflective thermal insulation, and use the obtained data in further calculations.
\end{abstract}

\section{Introduction}

Nowadays, the use of reflective thermal insulation is limited by the fact that during the process of calculating the thermal protection of building envelope, the surface emission factors are not taken into account. In different scientific works and regulatory documents, it is noted that the reflective thermal insulation increases the heat protection properties of the air cavities [1-7], but nowhere is indicated about the increase of the thermal protection of the outer walls in the presence of reflective thermal insulation on the inner surface. Therefore, when designing external walls, the energy-saving effect of reflective thermal insulation is not taken into account. At the same time, it should be mentioned that theoretical studies of the effect of reflective thermal insulation, installed on the wall behind the heating device, on heat loss through this part of the wall were carried out by the author and reported in works [8-9]. However, there was no experimental research in this direction.

\footnotetext{
* Corresponding author: n.umniakova@mail.ru
} 
Therefore, the complex of thermal engineering studies was conducted in climatic chambers of NIISF RAASN aimed at developing a methodology for assessing the effectiveness of the use of reflective insulation on the inner wall surface.

\section{Laboratory studies}

To carry out laboratory studies, the experimental wall structure was constructed from blocks of cellular concrete with a density of $560 \mathrm{~kg} / \mathrm{m}^{3}$ and a thickness of $300 \mathrm{~mm}$. The experimental wall construction was divided into 3 parts (fragment): one fragment consisted of blocks of cellular concrete and did not have on its inner surface neither polyethylene film, no reflective thermal insulation on the basis of aluminium foil; the second fragment consisted of blocks of cellular concrete and had in its composition a layer of reflective thermal insulation of aluminium foil (Armafol type) on the inner surface of wall, facing the warm compartment of the climatic chamber; the third fragment consisted of blocks of cellular concrete, and had in its composition a layer of polyethylene film on the inner surface of the blocks facing the warm compartment of the chamber. To exclude the mutual influence on each other fragments with reflective insulation and with plastic film a thermal barrier of polystyrene width $200 \mathrm{~mm}$ was made between the parts the experimental construction.

On the inner surface of each of the fragments of the experimental wall structure, temperature and heat flux sensors were installed according to the above scheme and temperatures and heat fluxes were obtained on the fragments of the experimental design (Fig. 1). The results of measurements of the temperature at the surface and in the thickness of each fragment of the experimental design, as well as the air temperature in the warm compartment of the chamber, are shown in Fig. 2 - Fig. 4.

a)

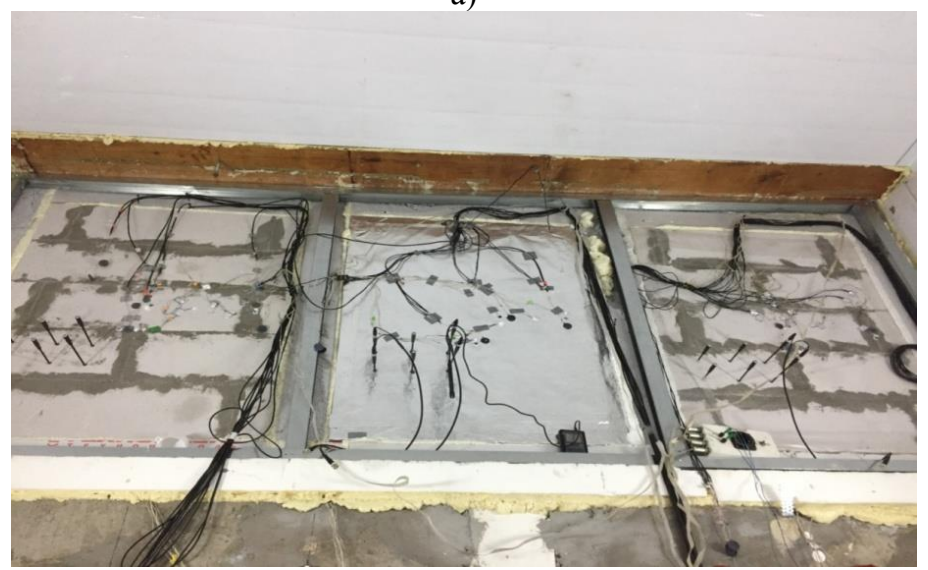

b)

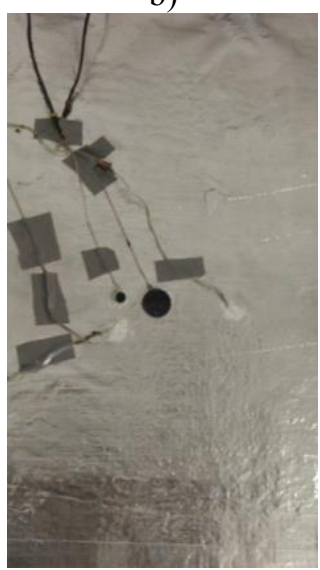

Fig. 1. An experimental wall structure made of cellular concrete blocks consisting of three fragments: without a screen of reflective thermal insulation and polyethylene (left), with a screen of reflective thermal insulation based on aluminum foil (center) and coated with polyethylene film (right).

a) general view of the experimental wall structure; b) section with a reflective thermal insulation

Based on the analysis of the results of thermal engineering studies and temperature measurements on the surfaces of three fragments of the experimental wall structure, a thermos-physical model of the heat exchange of the experimental construction with the surrounding walls of the warm compartment of the climatic chamber was developed. This model was compiled for three fragments of an experimental wall structure made of cellular concrete: one with a surface of cellular concrete; another with the coating of the inner surface with reflective thermal insulation on the basis of aluminum foil; the third with an 
inner surface covered with a polyethylene film. Based on the heat transfer by radiation for the considered variants of the experimental wall structure, a thermos-physical model for determining the coefficient of radiant heat exchange is adopted, taking into account the closed volume of the room (warm compartment of the climate chamber), including the surfaces of the walls, ceiling, and floor and their heat exchange by radiation with the surfaces of fragments of the investigated wall enclosure facing in cold compartment of the climatic chamber. To determine the coefficient of heat transfer by radiation, according to the adopted model, the equation is introduced:

$$
\alpha_{v . l .}=\frac{1}{\frac{1}{C_{v . p}}+\frac{1}{C_{v . p . f .}}-\frac{1}{C_{0}}}\left[\left(\frac{t_{v \cdot p .}+273}{100}\right)^{4}-\left(\frac{\tau_{v . p . f}+273}{100}\right)^{4}\right] \div\left[t_{v \cdot p}-\tau_{v . p . s r}\right],
$$

where $\mathrm{C}_{\mathrm{v} . \mathrm{p} .}$ - average coefficient of radiation of internal surfaces of warm separation of the climatic chamber, $\mathrm{W} /\left(\mathrm{m}^{2}{ }^{0} \mathrm{C}^{4}\right) ; \mathrm{C}_{\mathrm{v} . \mathrm{p} . \mathrm{f}}$ - is the emissivity of the inner surface of the fragment under investigation, $\mathrm{W} /\left(\mathrm{m}^{20} \mathrm{C}^{4}\right) ; \mathrm{C}_{0}$ is the emissivity of an absolutely black body

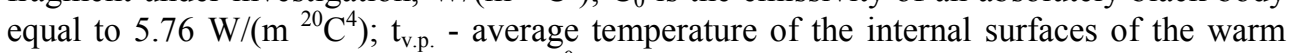
compartment of the climatic chamber, ${ }^{0} \mathrm{C} ; \tau_{\text {v.p.f. }}$-s the temperature of the inner surface of the fragment under study, ${ }^{0} \mathrm{C}$.

Thermal engineering studies of three fragments of the experimental wall structure were carried out at air temperature in a warm compartment $\mathrm{t}=23.3^{\circ} \mathrm{C}$ and in a cold one at $\mathrm{t}=$ $12.3^{\circ} \mathrm{C}$. In this case, the average value of the radiation coefficient of the internal surfaces was $\mathrm{C}_{\text {v.p. }}=5.18 \mathrm{~W} /\left(\mathrm{m}^{2}{ }^{0} \mathrm{C}^{4}\right)$. The radiation coefficient of the inner surface of the fragment of the experimental design in the presence of a reflective thermal insulation is $\mathrm{C}_{\mathrm{v} \text {.p.f. }}=0.5$ $\mathrm{W} /\left(\mathrm{m}^{2}{ }^{0} \mathrm{C}^{4}\right)$; and in its absence, the $\mathrm{C}_{\text {v.p.f. }}=5.23 \mathrm{~W} /\left(\mathrm{m}^{2}{ }^{0} \mathrm{C}^{4}\right)$;. The average temperature of the internal surfaces of the climatic chamber is $23.3^{\circ} \mathrm{C}$.

The results of thermal engineering studies of the distribution of temperatures from the inner surface along the thickness of fragments of the experimental design and to the outer surface are given below in Fig. 2 - 4. The temperature distribution in the fragment of the experimental wall structure, which has a reflective thermal insulation on the inner surface facing the warm compartment of the climatic chamber is shown on Fig.3. The temperature on its inner surface was $\tau_{\text {v.f. }}=17.5{ }^{\circ} \mathrm{C}$. For the fragment of the experimental wall structure without reflective thermal insulation, the temperature distribution is shown in Fig. 2 On its inner surface, the temperature is $\tau_{\mathrm{v} .}=20.02{ }^{\circ} \mathrm{C}$. The temperature on the surface of the fragment of the experimental design with a polyethylene film, as seen in Fig. 4 , is $\tau_{\text {v.p.f. }}=$ $20.14{ }^{\circ} \mathrm{C}$.

The radiant heat transfer for the inner surfaces of the investigated fragments of the experimental wall structure is determined by formula (1) for the following variants:

- Wall surfaces from blocks of cellular concrete in the absence of reflective thermal insulation:

$$
\alpha_{v . l .}=\frac{1}{\frac{1}{5,18}+\frac{1}{5,23}-\frac{1}{5,76}}\left[\left(\frac{23,3+273}{100}\right)^{4}-\left(\frac{20,02+273}{100}\right)^{4}\right] \div[23,3-20,02]=4,69
$$

- in the presence of a reflective thermal insulation:

$$
\alpha_{v . l .}=\frac{1}{\frac{1}{5,18}+\frac{1}{0,5}-\frac{1}{5,76}}\left[\left(\frac{23,3+273}{100}\right)^{4}-\left(\frac{17,50+273}{100}\right)^{4}\right] \div[23,3-17,50]=0,505
$$




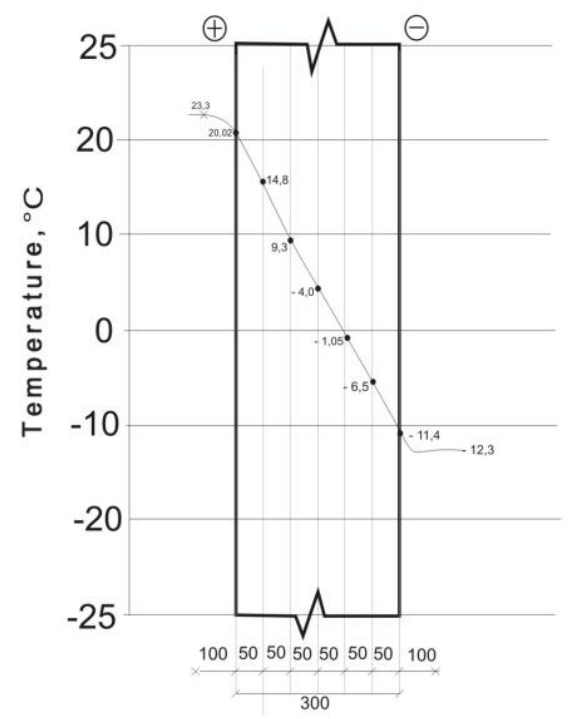

Fig. 2. The temperature distribution over the thickness of the experimental wall structure of $300 \mathrm{~mm}$ of cellular concrete from the inner to the outer surface in the absence of reflective thermal insulation and a polyethylene film

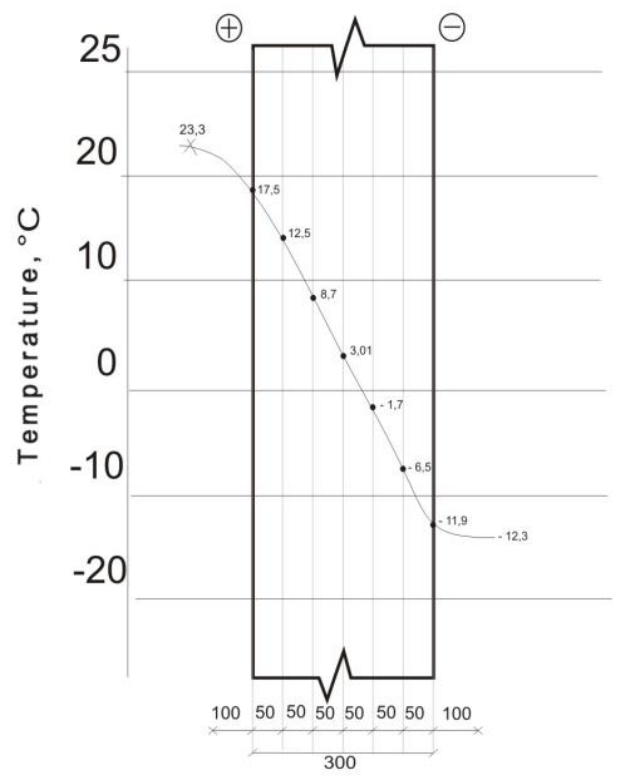

Fig. 3. The temperature distribution over the thickness of the experimental wall structure of $300 \mathrm{~mm}$ of cellular concrete with reflective thermal insulation on inner surface

- in the presence of a polyethylene film :

$$
\alpha_{v . l .}=\frac{1}{\frac{1}{5,18}+\frac{1}{5,24}-\frac{1}{5,76}}\left[\left(\frac{23,3+273}{100}\right)^{4}-\left(\frac{20,14+273}{100}\right)^{4}\right] \div[23,3-20,14]=4,93
$$




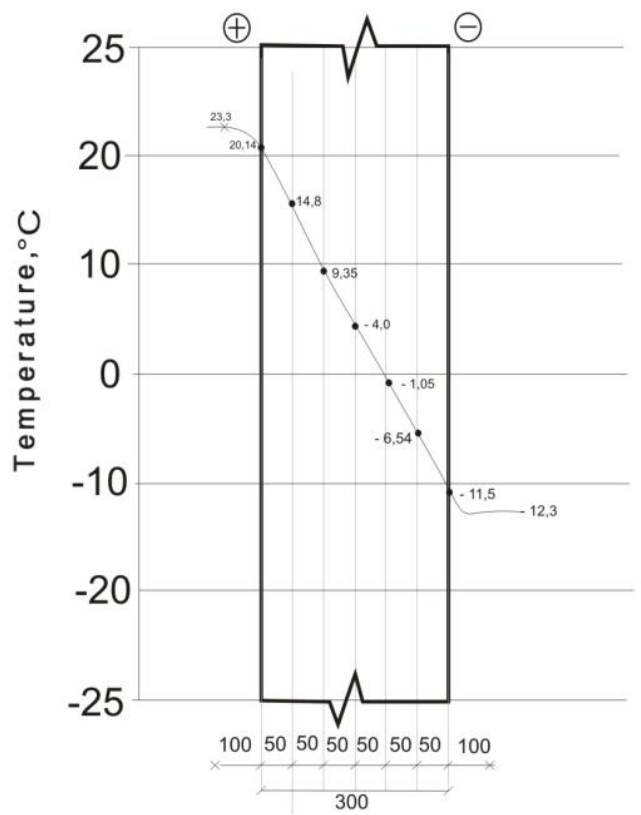

Fig. 4. The temperature distribution over the thickness of the experimental wall structure of $300 \mathrm{~mm}$ of cellular concrete with polyethylene film on inner surface

The value of the convective heat transfer coefficient for internal surfaces is determined by formula (2):

$$
\alpha_{v, k .}=1,66 \cdot \sqrt[3]{t_{v, p .}-\tau_{v . p . f .}}
$$

Calculated coefficient of heat transfer by convection for the surfaces of the fragments under investigation equal to:

- in the presence of a reflective thermal insulation based on aluminum foil

$\alpha_{\text {v.k. }}=1.66 \sqrt[3]{(23.3-17.5)}=2.97 \mathrm{~W} / \mathrm{m}^{20} \mathrm{C}$,

- for the surface with blocks of cellular concrete in the absence of reflective thermal insulation

$\alpha_{\text {v.k. }}=1.66 \sqrt[3]{3.28}=2.46 \mathrm{~W} / \mathrm{m}^{2}{ }^{0} \mathrm{C}$,

- for a surface with a polyethylene film

$\alpha_{\text {v.k. }}=1.66 \sqrt[3]{3.16}=2.43 \mathrm{~W} / \mathrm{m}^{2}{ }^{0} \mathrm{C}$.

The coefficient of heat transfer at the inner surface of the wall structure with reflective thermal insulation on the basis of aluminum foil was $\alpha_{\mathrm{v} . \mathrm{f} .}=\alpha_{\mathrm{v} . \mathrm{k} . \mathrm{f}}+\alpha_{\mathrm{v} . \mathrm{l.f}}=0,505+2,97=$ $3,47 \mathrm{~W} / \mathrm{m}^{2}{ }^{0} \mathrm{C}$, at the surface of blocks of cellular concrete in the absence of reflective thermal insulation $\alpha_{\mathrm{v}}=\alpha_{\mathrm{v} . \mathrm{k}}+\alpha_{\mathrm{v} .1 .}=4,82+2,46=7,28 \mathrm{~W} / \mathrm{m}^{2}{ }^{0} \mathrm{C}$ and in the presence of a polyethylene film $\alpha_{\mathrm{v}}=\alpha_{\mathrm{v} . \mathrm{k}}+\alpha_{\mathrm{v} .1 .}=4.93+2.46=7.36 \mathrm{~W} / \mathrm{m}^{2}{ }^{0} \mathrm{C}$.

Thus, the conducted thermal engineering studies have made it possible to establish that the value of the heat transfer coefficient for a device on the inner surface of a wall structure of a reflective thermal insulation and in the absence of a reflective thermal insulation decreases by $7.28: 3.47=2.09$ times.

This regularity, obtained for the first time on the basis of the conducted thermal engineering experimental studies, can be included in the Code of Regulations in the following edition:

"For internal surfaces of external walls with a reflective thermal insulation on their internal surface, the coefficient of heat transfer $\alpha_{\mathrm{v}}$ should be taken equal to $4.35 \mathrm{~W} / \mathrm{m}^{2}{ }^{0} \mathrm{C}$ ", 
while the resistance to heat exchange of the external wall structure will be $R_{v}=0,23 \mathrm{~m}^{2}$ ${ }^{0} \mathrm{C} / \mathrm{W}$.

\section{References}

1. K. Fokin, Building heat engineering of enclosing parts of buildings (Moscow: ABOKPRESS, 2006)

2. V. Bogoslovsky, Building Thermophysics. Thermophysical basis of heating, ventilation and air conditioning. (Higher School, Moscow, 1982)

3. SP 50.13330.2012 Code of Practice «SNiP 23-02-2003 Thermal protection of buildings. Updated version» (In Russian) (2013)

4. N.P. Umnyakova, Zhilishchnoye stroitel'stvo, 1-2 16 (2014)

5. A. Akhremenkov, V. Kuzmin, A. Tsirlin, V. Tsygankov, Construction Materials 12 (2013)

6. N.P. Umnyakova, V.A. Kuzmin, Zhilishchnoye stroitel'stvo, 6 (2016)

7. P.P. Oleinikov, Research of heat protection properties of shielded external walls of industrial refrigerators in the conditions of the south of Russia. (Volgograd: Thesis Abstract of Candidate of Technical Sciences, 2006).

8. N.P. Umnyakova, Zhilishchnoye stroitel'stvo, 216 (2015)

9. N.P. Umnyakova, Procedia Engineering, 111 (2015) 